\title{
Potencialidades del Municipio para el desarrollo local en Venezuela*
}

\author{
López Valladares, Mirtha**
}

\section{Resumen}

El presente trabajo tiene como objetivo explorar las potencialidades que tienen los municipios venezolanos como unidad básica de gobiemo, para contribuir de acuerdo a sus competencias legales, al desarrollo local. El análisis se realiza con base en los aportes bibliográficos y en los documeńtos normativos del régimen municipal, considerando los avances que ha logrado la práctica de la gestión municipal y el proceso de descentralización. Se discute el alcance de la autonomía local y el potencial de las competencias municipales como fuente promotora del desarrollo. Se concluye que las mayores posibilidades del ayuntamiento para promover el desarrollo local están en su capacidad para estimular la participación de la sociedad civil en el diseño, ejecución y control de políticas de desarrollo local.

Palabras clave: Autonomía, competencias municipales, desarrollo local, descentralización, Municipio, Venezuela.

\section{Municipal Potential in Local Development in Venezuela}

\section{Abstract}

The objective of this research is to explore the possibilities that Venezuelan Municipalities have as a basic governmental unit, to contribute towards local development according to their legal mandate. The analysis is carried out based on bibliographical support and on the normative documentation underlying the municipal regime, and considers practical advances that have been achieved in municipal management and in the decentralization process. The extent of local autonomy is

Recibido: 00-09-01. Aceptado: 01-02-06

* Este trabajo constituye un avance del Proyecto de Investigación titulado "Modernización Administrativa Ejecutada por los Órganos de la Administración Central de la Alcaldía del Municipio Maracaibo del Estado Zulla, durante el periodo 1995-1998*, financiado por el Consejo de Desarrollo Científico y Humanístico (CONDES-LUZ).

* Magíster en Gerencia Pública. Protesora Agregada de la Universidad del Zulia (LUZ). Investigadora del Centro de Estudio de la Empresa de la Facultad de Ciencias Económicas y Sociales de LUZ. Maracaibo-Venezuela. E-mail: lopezmirtha @ hotmail.com. Telefax: (58-261)-7596560. 
discussed and potential municipal capacities as a promoter of development. The conclusion is that the greatest municipal potential lies in its capacity to stimulate civic participation in the design, execution and control of local development policy.

Key words: Autonomy, municipal areas of competence, local development, decentralization, municipality, Venezuela.

\section{Introducción}

En toda sociedad organizada, la gestión gubernamental es un factor importante para tomar decisiones e impulsar acciones que puedan contribuir a su desarrollo o lesionarlo. Y la gestión municipal, por ser la más cercana a las necesidades y demandas de la población, tiene mayores posibilidades de aumentar su capacidad para dar respuestas pertinentes.

Dado que el funcionamiento de la administración pública está regulado por un marco normativo, es indudable la importancia del mismo, en tanto establece posibilidades y limitaciones a las instituciones gubernamentales. En el caso de los municipios venezolanos, si bien es cierto que cuentan con autonomía politica para formular sus propias leyes, no necesariamente se encuentran en las mejores condiciones para impulsar el desarrollo local.

La intención de este trabajo es explorar las potencialidades de los municipios venezolanos como unidad básica de gobierno para contribuir, de acuerdo a sus competencias legales y a las restricciones del contexto actual, al desarrollo local. El análisis se realiza con base en los aportes bibliográficos sobre el tema y los documentos normativos del régimen municipal.

\section{Concepción Jurídica del Municipio Venezolano}

El municipio, integrado por un conjunto de familias que viven en un centro poblado común, fue reconocido jurídicamente desde la antigüedad como la ciudad principal y libre, constituida por una comunidad humana, asentada en un territorio determinado, que administra sus propios y determinados intereses y depende siempre, en mayor o menor grado, de una entidad pública superior: el Estado nacional o provincial. El municipio se rige por sus propias leyes, siendo la unidad política primaria y autónoma de la organización nacional, cuyos vecinos pueden obtener y disfrutar derechos como ciudadanos. Por lo tanto, todo municipio debería contar con población, territorio y riqueza suficiente para sostener el funcionamiento de los servicios públicos indispensables a la satisfacción de necesidades originadas de las relaciones de vecindad. La organización de los municipios suele variar de unos estados a otros, pero generalmente el ayuntamiento está integrado básicamente por el alcalde y un cuerpo colegiado y deliberante, que es el órgano de representación o concejo (Cabanellas, 1979: 492; CBV, 1999: art.168; Serra Rojas, 1999: 99,761; Fuenmayor et al, 2000: 105).

En síntesis, el municipio es la entidad política y sociocultural que sirve de 
base para la división politico territorial y la organización administrativa de los estados de la república, constituyendo la célula básica de la división política del país (IAPEM, 1997:2).

Para ejercer el gobierno local, la Constitución de la República Bolivariana de Venezuela (Asamblea Nacional Constituyente, 1999: en su artículo 169), expresa que la ley podrá establecer: "... diferentes regimenes para su organización, gobierno y administración, incluso en lo que respecta a la determinación de sus competencias y recursos, atendiendo a las condiciones de población, desarrollo económico, capacidad para generar ingresos fiscales propios, situación geográfica, elementos históricos y culturales y otros factores relevantes En particular, dicha legislación establecerá las opciones para la organización del régimen de gobierno y administración local, que corresponderá a los Municipios con población indígena. En todo caso, la organización municipal será democrática y responderá a la naturaleza propia del gobierno local".

La Constitución Bolivariana prevee por primera vez la posibilidad de opciones para la organización y gobierno de los municipios con población indígena, tal como se expresa en el mencionado artículo; brindándole la oportunidad de participar en los cuerpos deliberantes de los diferentes niveles de gobiernos. Así mismo incorpora la participación ciudadana en la gestión pública.

Es decir, en Venezuela la ley permite variedad de regímenes municipales, autorizando la agrupación de los municipios en distritos y también la formación de mancomunidades para determinados fines de la competencia municipal.
Aunque existen problemas comunes a varios municipios, no hay un ámbito de representación institucional de los mismos que facilite la negociación intermunicipal, asi como entre los municipios y el gobierno regional, en forma transparente; aunque la posibilidad de integración y cooperación entre municipios está contemplada en la nueva Constitución y en la vigente (1989) Ley Orgánica de Régimen Municipal (LORM), respecto a las mancomunidades, las condiciones y la práctica de gobierno no favorecen su desarrollo. En Venezuela, igual que en otros paises, buena parte del esfuerzo de los gobiernos municipales se pierde en la lucha por la asignación de recursos (Cormick, 1997: 111).

La normativa que rige las entidades locales y, fundamentalmente a los municipios, se establece en el articulo 169 de la Constitución Bolivariana, en las leyes orgánicas que desarrollan los principios constitucionales sobre los municipios especialmente la Ley Orgánica de Régimen Municipal, en las disposiciones legales pertinentes que dictan los órganos legislativos regionales, $y$ finalmente en las ordenanzas municipales, preservando la jerarquía de los instrumentos legales.

Un aspecto político-administrativo característico del municipio, lo constituye como se mencionó anteriormente, la posibilidad de diversas formas de agrupación local, bien sea en distritos metropolitanos o en mancomunidades para determinados fines de su competencia, asi como otras formas asociativas descentralizadas municipales, con personalidad jurídica, tales como institutos autónomos y empresas municipales lo cual se encuientra contemplando en el artículo 170 
y 171 de la CBV, y en el artículo 13 y 76 de la LORM.

Los distritos metropolitanos según el artículo 24 la Ley Orgánica de Régimen Municipal, son entidades de carácter público que agrupan en cornubación dos o más municipios que constituyen una región urbana con intereses comunes $y$, han llegado a constituir una unidad urbana económica y social, con más de doscientos cincuenta mil habitantes.

\section{Responsabilidad del Municipio ante el Desarrollo Local}

Aunque el marco normativo municipal es básico, no puede olvidarse que el país está en un proceso de reforma de la administración pública, en el contexto de los cambios mundiales que afectan el funcionamiento del Estado: globalización, esfuerzos multinacionales por diluir las fronteras nacionales, informatización de la sociedad, competencia, entre otros. Este proceso enfrenta dos tendencias: la que enfatiza la reducción del tamaño del Estado frente a la que reclama su fortalecimiento o reestatización para entrentar nuevas responsabilidades, especialmente en el ámbito local.

Independientemente de cuál opción se haga, es indudable que está en discusión la redefinición del rol del Estado y la del Municipio en particular; por lo tanto, la época actual exige discutir la pertinencia del marco jurídico vigente y reclama reformulaciones en distintos aspectos, no sólo para adecuarlo a la Constitución de 1999 , sino también para fortalecer el rol del municipio en el desarrollo local.

Es razonable suponer que una organización pública orientada por un mo- delo burocrático centrado en sus propios intereses y por lo tanto básicamente autorreproductivo no tienen capacidad suficiente para mejorar la capacidad de intervención gubernamental sobre la sociedad y para atender a sus nuevas demandas. Este modelo de gestión produce algunos impactos no deseados (Cormick, 1997:113):

- Los usuarios/clientes no reciben los servicios esperados o los reciben sin cumplir con los requisitos mínimos de calidad.

- El gobierno local no logra ser identificado como actor clave en decisiones relacionadas con la sociedad; el vínculo más fuerte con la comunidad es una actividad orientada a obtener recursos para paliar el déficit fiscal.

- No se prioriza la gestión de personal y no se mejora su capacitación, lo cual afecta el prestigio de la administración local.

Osborne y Gaebler (1994: 57) recogen el enfoque de un alcalde estadounidense sobre el nuevo rol de la gestión local, en oposición a la concepción tradicional de recaudar impuestos y prestar servicios: "El gobierno municipal tendrá que realizar ciertos ajustes y, en cierto modo, redefinir su papel tradicional. Creo que el ayuntamiento definirá más a menudo su función como la de un catalizador y un facilitador. Se descubrirá a sí mismo más en la función de definir problemas y de reunir luego recursos para que otros los utilicen en la solución de estos problemas... El gobierno municipal tendrá que dirigir aún esfuerzos a entretejer los escasos recursos públicos y privados a fin de alcanzar las metas de nuestra comunidad". 
Según Cormick (1997: 106,117) la reformulación del rol del municipio y su fortalecimiento institucional implican un proceso de reestatización, en el sentido de recuperar algunas funciones actualmente muy debilitadas en los ámbitos nacional y regional: a) la función legislativa, como respuesta a las demandas de la sociedad y como expresión de pluralidad política; $y$ b) la función de control sobre el Ejecutivo. Para garantizar una eficaz reformulación del municipio se requiere según este autor, mayor autonomía institucional y financiera, eficiencia en el manejo de sus recursos, participación de la comunidad, cooperación intermunicipal activa y, mejoramiento de su propia capacidad de gestión.

Los nuevos roles del municipio, en un contexto de reconstrucción de las funciones estatales y de fortalecimiento del gobierno local exigen que los dirigentes públicos se comprometan con la ejecución de una acción a largo plazo, que puede seguir diferentes estrategias, de acuerdo a la naturaleza del área de actividad (Frost-Kumpf et al, 1998: 195).

Esencialmente el municipio debe poner su esfuerzo en el mejoramiento de la calidad de vida de sus habitantes. Esto incluye, además de los aspectos más clásicamente ambientales, la defensa de los espacios públicos, de las libertades, del desarrollo social y cultural, la producción de bienes y servicios, la generación de empleos productivos, entre otros.

En este contexto, la gestión municipal está adquiriendo cada vez mayor relevancia ante la posibilidad de mejorar la gestión del sector público, a través del desarrollo institucional capaz de promover el desarrollo local en todas sus dimensiones.
Históricamente es un hecho que las grandes corporaciones e incluso los pequeños negocios dependen del gobierno desde su origen (créditos, permisos de funcionamiento y ubicación, otros), ante el riesgo de morir (créditos, leyes de bancarrota, fusión y antimonopólicas) y en momentos intermedios (incentivos tributarios, recursos provenientes de contratos y préstamos gubernamentales, planes de capacitación laboral, entre otros). De alli que la influencia de los diferentes niveles de gobierno en las empresas privadas es honda y de gran significación, especialmente en el nacional y el municipal (Bozeman, 1998: 72).

Los últimos años han demostrado la importancia de los municipios para el desarrollo económico, impulsando políticas municipales que trascienden las competencias formalmente asignadas, para facilitar la inserción en la actividad económica global. Aunque, esto no debe limitar la atención a la solución de los problemas sociales (Castells, 1999:294-5).

Otros autores como Brockmann (1998:62) opinan que la política económica no debe estar aislada de la social, puesto que la evaluación del crecimiento requiere conocer cuáles han sido los bienes y servicios que han experimentado un aumento, asi como quienes se han beneficiado de ellos y en qué grado. Es decir una política económica con orientación social, no puede limitarse solo a incrementar la producción y el abastecimiento, sino que debe buscar la participación en el empleo y en el consumo, del mayor porcentaje posible de la población.

El enfoque neoinstitucionalista afirma que las instituciones juegan un papel crucial en la dinámica y desarrollo de 
cualquier sistema económico- social, por cuanto generan sistemas de incentivos o desestímulos económicos y extra económicos, que inducen en los individuos intercambios complejos tales como inversión, ahorro, innovación tecnológica, acciones colectivas e individuales (Ayala, 1999: 349).

Por lo tanto, siguiendo el enfoque neoinstitucionalista, el gobierno municipal puede establecer determinadas reglas del juego que inciten a las organiza. ciones de la sociedad civil -empresas, gremios, ONG's, organizaciones vecinales- a involucrarse en el diseño, la administración y/o ejecución de políticas públicas para el desarrollo local.

Ahora bien, en la sociedad moderna predomina la movilidad de los factores de producción, el desplazamiento constante de los centros de actividad económica y el gusto por la innovación. En este espacio turbulento juegan un rol fundamental el innovador, el emprendedor y el científico, sujetos que aportarán al desarrollo local siempre que integren la racionalidad instrumental con la identidad cultural (Touraine, 1999: 153-4).

Aunque el diseño de la política de desarrollo, no es potestad exclusiva del municipio, puede influir en ella, tomando en cuenta el contexto nacional, latinoamericano y mundial. Los países de América Latina están sufriendo profundos cambios estructurales, producto de la era informática que 'materializó un nuevo modo de producir, comunicar, gestionar y vivir' que se ha globalizado. En este contexto, los gobiernos deben asumir su responsabilidad en el diseño de políticas de desarrollo, considerando el posible efecto positivo en las condiciones de vida de la población (Castell, 1999: 31; Yuralivker, 1992: 99).

Por lo tanto, los gobiernos municipales requieren un grado de libertad y capacidad de decisión acerca de las acciones a desarrollar en el ámbito de sus competencias y responsabilidades, que les permita impuisar el fortalecimiento institucional y el desarrollo local.

\section{Autonomía local}

En sentido general, la autonomía se refiere a la condición del pueblo que goza de independencia política plena. Esta condición ideal y absoluta no es fácil de encontrar, de modo que en un sentido más operativo, para el caso que se estudia en este trabajo, se considera la autonomía como la potestad que tienen los municipios para regir los intereses intrínsecos de la vida local e impulsar el desarrollo, mediante normas y órganos propios de gobierno.

Según Castells (1999:292) la autonomía local se basa en la idea de que son los ciudadanos los que están mejor ubicados para juzgar la acción del gobierno y que deben potenciarse mecanismos que permitan a los gobiernos locales decidir acerca de los asuntos que les competen y ser efectivamente responsables de sus acciones ante la comunidad.

La autonomia municipal desde el punto de vista jurídico es la facultad del municipio como persona jurídica pública territorial para administrarse y gobernarse a sí mismo, en el ámbito de su competencia para cumplir los fines públicos legales que le han sido asignados y explotar creadoramente las potencialidades locales sin la intervención de otros poderes 
públicos, haciendo uso de sus órganos de gobierno (Ruiz, 1993: 115; Fuenmayor et al, 2000: 105).

La Constitución Bolivariana de Venezuela en su artículo 168, consagra la autonomía municipal y las materias que comprende, las cuales se expresan en el artículo 10 de la LORM.

Eliécer Ruiz (1993: 120-122) analiza en forma rigurosa cómo se establece jurídicamente el carácter autonómico de los municipios y la legitimidad Constitucional de la intervención de otras ramas del Poder Público en la delimitación de la autonomia. Según Ruiz, para la Corte Federal y de Casación el 02-12-1937, “... aunque desde el punto de vista sociológico puede afirmarse que la autonomía municipal es emanación del pueblo... se la considera emanada exclusivamente de la Constitución, porque es ésta la que distribuye el Poder Público entre el Poder Federal, el de los estados y el municipal y les señala sus respectivos límites". En forma similar el 13-11-89 la Corte Suprema de Justicia ratifica lo anterior, recogiendo argumentos de la Exposición de Motivos de la Constitución de 1961 vigente para ese momento y del capítulo sobre los municipios, los cuales expresan normas flexibles que dan la posibilidad al legislador ordinario de organizar mejor numerosos aspectos de la vida política, como los detalles del régimen municipal, pero sólo para desarrollar los principios constitucionales y considerando las estipulaciones de las leyes orgánicas, intermedias entre la norma constitucional y la ley ordinaria. En consecuencia, Ruiz destaca que la Constitución de 1961 consagraba la autonomía municipal con carácter relativo, no absoluto. La autonomía municipal, tanto en la Constitución de 1961 como en la de 1999 , comprenden los mismos elementos y establecen que los actos de los municipios no podrán ser impugnados sino ante los órganos jurisdiccionales competentes.

Los diferentes tipos de autonomía municipal posibles, son clasificados por Eliécer Ruiz (1993: 120) de la siguiente manera: "la autonomía del Municipio comprende la elección de sus propias autoridades (autonomía política); la libre gestión en las materias de su competencia (autonomia normativa); la creación y recaudación de impuestos (autonomía tributaria) y la inversión de sus propios ingresos (autonomía administrativa)". De esta manera el autor diferencia dos tipos de autonomía acerca de los ingresos, separando la obtención de la inversión.

Desde un punto de vista estrictamente administrativo la clasificación antes mencionada puede ser discutible; la referencia constitucional (1999) a la "gestión de las materias de su competencia" no es otra cosa que la obtención, coordinación y dirección de los recursos humanos, materiales, técnicos y financieros para prestar los senvicios públicos que están bajo su responsabilidad, cuestiones que constituyen la esencia del proceso administrativo o de gestión siguiendo a Ochoa y Gamboa (1983). En consecuencia, la autonomía podría clasificarse simplemente en política y administrativa, la primera referida más directamente al ejercicio relativo del poder de elegir y gobernar, y la segunda referida al funcionamiento de las organizaciones municipales; ambas están reguladas por las normas correspondientes, to cual les imprime carácter normativo. 


\subsection{Autonomía política}

La autonomía política se refiere a la potestad del municipio de elegir sus autoridades y dirigir sus asuntos según leyes propias (Cabanellas, 1979:423). En Venezuela, el Constituyente ha conferido esta potestad al municipio, a los fines de que este se autogobierne, lo cual implica la elección de sus autoridades a través de mecanismos que la propia Constitución y otras leyes complementarias establecen, siendo requisito fundamental que el gobierno sea democrático. De manera que la Nueva Constitución venezolana no concibe al municipio sin su autonomía política y ésta a su vez, sin su carácter democrático, representativo y participativo (art.169). Esta concepción coincide parcialmente con lo expresado en la LORM en sus artículos 3 y 10, aunque la CBV enfatiza el carácter participativo y protagónico, multiétnico y pluricultural.

La autonomía política regional y municipal se profundizó al instituir la elección directa de Gobernadores y Alcaldes; como expresión de la descentralización política se crea en el artículo 51 de la Ley Orgánica de Régimen Municipal, la figura del alcalde, al señalar que en cada Municipio o Distrito Metropolitano se elegirá un alcalde por mayoría relativa, en votación universal, directa y secreta con sujeción a lo dispuesto en 1997 en la Ley Orgánica del Sufragio y Participación Política (LOSPP). En cuanto al período del poder público municipal, la CBV en su artículo 174 consagra: "El Alcalde o Alcaldesa será elegido o elegida por un período de cuatro años por mayoría de las personas que votan, y podrá ser reelegido o reele- gida, de inmediato y por una sola vez, para un período adicional".

El impacto de la descentralización política, a pesar de la alta abstención electoral, es recogido por Rafael de la Cruz (1992: 22): "Las primeras elecciones de gobernadores y alcaldes realizadas en diciembre de 1989, transformaron radicalmente los mecanismos de representación; los mandatarios regionales y locales están ahora sometidos al control electoral y a presiones cotidianas de esas mismas comunidades".

Por otra parte, como consecuencia de los esfuerzos por profundizar la democracia, en diversos países latinoamericanos comenzó un proceso de reforma de las constituciones nacionales y regionales, que en lo relativo al ámbito municipal puede ser condensado en la idea de autonomía. En Venezuela, el cambio constitucional sólo fue posible durante el proceso constituyente impulsado por el actual Presidente de la República Hugo Chávez, en este caso se mantiene la misma concepción de autonomía expresada ya en la Constitución de 1961.

En América Latina ha aumentado el número de municipios que elaboran su propia Carta Municipal, lo que expresa un grado avanzado de autonomía y de capacidad de decisión sobre su futuro institucional (Cormick,1997: 108). En el caso venezolano la legislación no concede expresamente esta potestad a los municipios, pero tampoco se lo niega.

La LORM en sus artículos 4 y 9 establece el derecho de los Concejos o los Cabildos, para formular normas de aplicación general enmarcadas en los principios constitucionales y las correspondientes le- 
yes orgánicas, sobre asuntos específicos de interés local; estas disposiciones se denominan Ordenanzas y tienen carácter obligatorio para los particulares, así como para las autoridades nacionales, estadales y locales. Las ordenanzas deben ser promulgadas por el alcalde y publicadas en la Gaceta Municipal.

\subsection{Autonomía administrativa}

La autonomía administrativa se refiere a la libre gestión en las materias que competen al municipio, establecidas en la Constitución Bolivariana (art.168) y las que le asignan las leyes orgánicas y especiales, pero con las limitaciones que dichas normas establecen, por ejemplo en materia de crédito público y de prestación de servicios públicos, lo cual se discutirá en la sección correspondiente a las competencias municipales.

La denominada autonomía financiera o fiscal, es entendida como la potestad que tiene el municipio de dictar sus propias normas de creación, recaudación e inversión de sus ingresos, de acuerdo a los principios que rigen cada materia, tanto en la Constitución Bolivariana como en determinadas leyes: El Código Orgánico Tributario (1994), la Ley Orgánica de la Hacienda Pública Nacional (1974) y en especial la LORM. De lo anterior se observa, desde el punto de vista del derecho que si los municipios tienen a dictar sus propias leyes, la autonomía fiscal debería ser considerada expresión de la autonomía política; sin embargo, por la naturaleza de la materia, relativa a la obtención de ingresos propios para cumplir con sus responsabilidades gubernamentales, puede entenderse como autonomía administrativa.

Siendo el municipio el poder gubernamental más cercano a la población, no es extraño que con frecuencia se le planteen demandas respecto a las cuales cuenta con poca capacidad de intervención. Esto lleva a las autoridades municipales a intervenciones reactivas, no necesariamente exitosas que contribuyen a desprestigiar a las instituciones locales. Por otra parte, vale la pena introducir en el análisis de una gestión municipal concreta la cuestión de los beneficiarios del gobierno local, lo cual puede determinarse verificando los problemas efectivamente resueltos haciendo uso de la autonomía administrativa $y$ en beneficio de quién se tomaron las decisiones y se ejecutaron las acciones correspondientes. Al respecto afirma Cormick (1997: 112 116) que en Argentina: "... el municipio... ha sido estructurado para dar respuesta a determinado tipo de problemática que no es, necesariamente, la más acuciante para los sectores sociales que reclaman hoy la atención estatal. (Un ejemplo lo constituye el tema del empleo y el más amplio de la promoción de la producción)... la gestión pública local es cuestionada por su debilidad para atender a tales demandas. Asi mismo, su propia debilidad la transforma en una institución rehén de otros niveles estatales que actúan sobre ella".

El autor considera que los sistemas locales están tensionados por dos tendencias extremas: en primer lugar, los municipios dependen individualmente de los aportes que les brinda algún centro de poder (el gobierno central o el regional). 
Esta situación reduce la autonomía y obliga a gestionar continuamente nuevos recursos para paliar la escasez de fondos. En segundo lugar, se generan feudos locales basados en el disciplinamiento polftico de la base electoral y de quienes financian las campañas, lo cual es utilizado como instrumento de negociación y como garantía de sobrevivencia política e institucional de los grupos políticos dominantes a nivel local (Osborne y Gaebler, 1994: 40; Cormick, 1997:111).

En consecuencia, no sólo desde el punto de vista jurídico es relativa la autonomía municipal; en la práctica, las presiones de los grupos de poder y los compromisos pre-electorales restringen también dicha autonomía.

\section{Descentralización y Competencias municipales para promover el desarrollo local}

Aunque el municipio ha sido considerado siempre la unidad básica de gobierno, al cual la Constitución le atribuye un conjunto de competencias, éstas históricamente han sido desplazadas y asumidas por los gobiernos regional y nacional. Es gracias al proceso de descentralización que el municipio vuelve a tener la oportunidad de asumir un rol protagónico en la prestación de servicios públicos, en correspondencia con las necesidades 10cales. Como afirma Blair (1993: 263): "La necesidad de descentralización es evidente. Las condiciones regionales difieren fuertemente de una provincia a otra $y$, dentro de una misma provincia, de un poblado al otro. A fin de serpor lo menos moderadamente efectivo, cual- quier proyecto de desarrollo debe poder encajar en dichas condiciones diferentes".

Es por ello que la descentralización, así como otros aspectos de la modernización administrativa, no constituyen un objetivo en sí mismos, ni se pueden realizar en condiciones controladas, como si se tratase de un experimento de laboratorio. La descentralización está al servicio de fines que tienen significación social, económica y política, los cuales no pueden lograrse en forma voluntarista, pues están restringidos o posibilitados por las particularidades de cada nación, de cada región o de cada localidad (Rojas, 1995:10). En el caso venezolano, aunque el tema ya se venía discutiendo, el proceso de descentralización se empezó a materializar después de los acontecimientos históricos ocurridos en los años 1989 y 1992: el alzamiento popular contra el ajuste económico impuesto por el segundo gobierno de Carlos Andrés Pérez a pocos días de su toma de posesión y dos intentos de golpe militar, los cuales cuestionaron la legitimidad del sistema político que imperaba en el país, así como la corrupción e ineficiencia de la administración pública.

En correspondencia con lo anterior, Rojas (1995; 12) reconoce que la descentralización en Venezuela careció inicialmente del apoyo activo y decisorio de los actores más influyentes dentro del gobierno y del aparato estatal en su conjunto, es sólo en junio de 1993, con la salida forzada del Presidente Carlos A. Pérez, que su sucesor Ramón J. Velásquez nombró Ministro de la Descentralización. Por la misma época se hizo más agresiva la reclamación descentralizadora de los 
gobernadores regionales, quienes constituyeron entonces su Asociación Nacional y reclamaron la facultad de nombrar a los directores de los organismos ministeriales descentralizados en su jurisdicción.

La descentralización venezolana ha contado con la Comisión Presidencial para la Reforma del Estado (COPRE), organismo de rango ministerial, con vocación de permanencia, destinado a la reforma de las instituciones del Estado y centrado en la evaluación y apoyo a la reforma de las instituciones políticas y administrativas. Venezuela se distingue favorablemente de otros países latinoamericanos que no han contado con un organismo de este tipo. La COPRE ha logrado vincular importantes fuerzas institucionales al proceso de descentralización, especialmente a la oficina de Coordinación Nacional y de Planificación CORDIPLAN ambos motivaron a otras instituciones públicas a sumarse en respaldo del proceso de la descentralización (Rojas, 1995:18).

Ahora bien, Mattos (1990:165-167) se pregunta acerca de la validez de la descentralización para lograr los objetivos que formalmente se propone, esto es, aumentar el poder, la autonomía de decisión y el control de los recursos, las responsabilidades y las competencias de las colectividades locales, en detrimento del poder de los órganos del gobierno central. Esto supuestamente permitiria promover el desarrollo local, democratizar los procesos sociales, aumentar la participación popular y reducir la injusticia social. Sin embargo, señala el autor, ¿cómo una reforma de tipo político administrativo puede lograr tan profundas transformaciones estructurales donde imperan tendencias contradictorias?
La descentralización es una de tantas modas de gestión pública copiadas de otros países donde han tenido éxito, que se han practicado por ensayo y error, hasta que su fracaso conduce a la aplicación de un nuevo paradigma. Pero la razón de fondo que impulsa hoy la descentralización está vinculada al desarrollo del capitalismo mundial: si bien el fortalecimiento de los Estados nacionales fue funcional a la constitución y expansión de las sociedades capitalistas de cada país, la transnacionalización cambia la percepción, considerando a estos Estados como un factor perturbador para la acumulación y crecimiento capitalista en la era de la globalización y la información (Mattos, 1990: 167-168).

Para comprender el alcance real de la descentralización hacia los municipios, es necesario precisar las competencias de los diferentes niveles de gobierno $y$ distinguir dos tipos de competencias: las exclusivas y las concurrentes. Las competencias exclusivas se pueden definir como aquellas facultades que por su naturaleza son propias de la Nación, de los Estados o de los Municipios, asignadas por la Constitución o la Ley que se las atribuyen (Savy, 1990:239).

La Ley Orgánica de Descentralización, Delimitación y Transferencia de Competencias del Poder Público prevé algunas competencias exclusivas para los estados: Organización, recaudación y administración del ramo del papel sellado; conservación, administración y aprovechamiento de las carreteras, puentes y autopistas en sus territorios; organización, recaudación, control y la administración de los impuestos específicos al consumo no reservados por ley al poder na- 
cional y, la administración y mantenimiento de puertos y aeropuertos públicos de uso comercial.

Al comparar las competencias asignadas a los diferentes niveles de gobierno en la Constitución, la Ley Orgánica de Descentralización, Delimitación y Transferencia de Competencias del Poder Público de 1989, la LORM, la Ley Orgánica de Ordenación Urbanística (LOOU) de 1987 y la Ley Orgánica para la Ordenación del Territorio (LOPOT) de 1983, sólo sería competencia exclusiva de los municipios el crédito popular. En la práctica hay suficientes evidencias de que esta competencia también ha sido ejercida por el gobierno nacional. Como ejemplo pueden mencionarse los diferentes programas de crédito popular, especialmente para microempresas, desarrollados por organismos ministeriales, como uno de los paliativos al desempleo.

Todas las demás competencias serían concurrentes; éstas se refieren a aquellos servicios que se prestan en forma compartida entre los tres niveles gubernamentales, bajo la dirección del gobierno central. Son competencias difíciles de ejercer, debido a su gran complejidad y al hecho de que son indispensables a toda la población, como los servicios de salud y educación. Efectuada la transferencia a las regiones, le corresponde al gobierno estadal ejecutar las políticas necesarias para la delegación de responsabilidades hacia los municipios, dado que en la Ley Orgánica de Descentralización, no están delimitadas las competencias correspondientes al nivel municipal.

Algunos estados como Falcón, Aragua, Lara, Zulia y otros presionaron al gobierno central para hacer efectivo el trasla- do de ciertas competencias, especialmente las relativas a salud y educación, asi como el manejo de puertos, aeropuertos, puentes y vías de comunicación, realizando los acuerdos correspondientes. Al respecto afirma Rojas (1995: 27,29): "Venezuela concibió de manera pionera el mecanismo de los convenios entre el gobierno central y los niveles subnacionales, y lo hizo respecto del núcleo principal del cuerpo de medidas que debe tomar la estrategia descentralista: la definición de las competencias que asumirán las entidades territoriales y los recursos precisos que se le trasladarán para cumplirlas. El instrumento de convenio es 10 suficientemente flexible como para acomodarse a la enorme heterogeneidad que caracteriza las unidades regionales y locales latinoamericanas... los convenios pueden ser instrumentos adecuados para trazar planes de metas y desempeño -principalmente planes de transformación organizacional- una vez asumida la nueva responsabilidad por parte de los niveles subnacionales, pero no para discutir las competencias a cargo de cada nivel de la administración pública".

La descentralización, como se dijo anteriormente no es un hecho fortuito. Aunque la decisión de iniciar el proceso responde a una propuesta de reforma impulsada por organismos multilaterales y fue respaldada con argumentos formales, tales como el logro de la eficiencia, la participación ciudadana, la prevención, la corrupción, entre otros; su ejecución se hace posible en la medida que las condiciones del contexto político, económico y social lo permiten y, presionan en su favor. Cormick (1997:106) considera que: "...las profundas transformaciones produ- 
cidas respecto a la dimensión y las competencias del estado nacional a lo largo de los últimos años han dado lugar a una reformulación equivalente de las competencias y roles de otras instancias estatales, vg, las provincias y los Municipios. No cabe duda, por otro lado, que buena parte de esta reformulación y redefinición de responsabilidades se ha instalado como un conjunto de hechos consumados ante los que las instituciones y los actores sociales han debido acomodar su accionar".

La Ley Orgánica de Descentralización, tiene como objeto "desarrollar los principios constitucionales para promover la descentralización administrativa, delimitar competencias entre el Poder Nacional y los Estados, coordinar los planes anuales de inversión de las Entidades Federales con las que realice el Ejecutivo Nacional en ellas y facilitar la transferencia de la prestación de los servicios del Poder Nacional a los Estados" (Ruiz, 1997:85).

Dado que la mencionada Ley no precisa las competencias que serán transferidas a los municipios, éstas dependerán de los procesos de negociación entre los órganos del poder local y estadal. Entre tanto, se mantiene vigente la distribución de competencias establecida en diferentes leyes, en el marco de las disposiciones constitucionales al respecto.

Según el artículo 178 la Constitución Bolivariana es de competencia municipal el gobierno y administración de los intereses peculiares de la entidad, en particular la ordenación y promoción del desarrollo económico y social, la dotación y prestación de los servicios públicos domiciliarios, la política inquilinaria con criterio de equidad, justicia y contenido social.
Las actuaciones que corresponden al municipio en la materia de su competencia no menoscaban las competencias nacionales o estadales que se definan en la ley conforme a la Constitución, es decir que a los municipios se le atribuye competencias en una serie de materias propias de la vida local.

El artículo 36 de la LORM establece el conjunto de competencias propias del municipio, las cuales se ejercerán sin prejuicio de las atribuidas a los órganos del poder Nacional, como por ejemplo el establecimiento de las tarifas de los servicios públicos, dentro del régimen de regulación de precios que le corresponde.

En el análisis de las competencias municipales es importante preguntarse cuáles son las reales posibilidades con que cuentan los gobiernos locales para generar opciones de gestión y formas diferentes de relación con la sociedad. En definitiva se trata de distinguir aquellas cuestiones sobre las cuales tiene capacidad de acción el gobierno municipal de aquellas en las que no puede intervenir (Cormick, 1997:107).

\section{A manera de conclusión}

La normativa municipal es compleja, porque contiene diversas disposiciones que afectan la administración local, delimitando sus responsabilidades $y$ abriendo un cúmulo de posibilidades de acción, a pesar de las restricciones legales. Por lo tanto, es necesario que las autoridades y funcionarios locales, así como la población del municipio, estén atentos para identificar en el entramado normativo los derechos y deberes que les corresponden $\theta$ impulsar su desarrollo. 
Las entidades municipales deben tener capacidad para administrar sus competencias y gobernarse a sí mismos; para ello existe la autonomía, que permite elegir sus autoridades y desenvolverse según sus propias leyes; la autonomía política se afianzó a partir de la reforma de la Ley Orgánica de Régimen Municipal, en 1989, que establece la elección de Alcaldes y Concejales; y la autonomía administrativa, que ofrece la oportunidad de crear y recaudar los impuestos municipales e invertir sus propios ingresos, está avanzando.

La autonomía del gobierno local no es absoluta, y no siempre la ejerce sin entrar en contradicción con otros niveles de gobierno, debido a las limitaciones que el marco normativo le establece al municipio, de acuerdo a la jerarquía de leyes: Constitución de la República Bolivariana de Venezuela, Leyes Orgánicas Nacionales (especialmente la Ley Orgánica de Régimen Municipal) y las Leyes Especiales, a las cuales se deben someter.

A pesar del rango constitucional que siempre ha tenido el municipio como eje del desarrollo local, no es sino a partir de comienzos de la década de los noventa con el proceso de descentralización que el municipio asume de nuevo un rol protagónico en la prestación de los servicios públicos en su jurisdicción. En este campo el gobierno municipal tiene un rol importante que cumplir, porque los servicios públicos son fundamentales tanto para el desarrollo económico como para el desarrollo de las condiciones de vida. Sin embargo, la calidad de los servicios y los beneficiarios efectivos de los mismos, dependen del alcance de la participación de la comunidad.
Por otra parte, el crecimiento económico siempre se ha producido bajo la protección gubernamental. De modo que la actuación del municipio en lo relativo al desenvolvimiento del sector privado, tanto en materia de incentivos fiscales como crediticia y de dotación de infraestructura, juega un papel fundamental.

El gobierno municipal puede establecer reglas del juego que inciten a las organizaciones de la sociedad civil -empresas, gremios, ONG's, organizaciones vecinales- a participar activamente en el diseño, control y/o ejecución de políticas públicas para el desarrollo local, a pesar que el diseño de la política de desarrollo, no es potestad exclusiva del municipio.

\section{Bibliografía citada}

Ayala Espino, José (1999). Instituciones y Economía. Una introducción al neoinstitucionalismo económico. Fondo de Cultura Económica, México.

Blair, Harry W. (1994). Modelos para integrar la planificación de desarrollo social y la implementación al nivel local. En pobreza. Un tema impostergable. Nuevas respuestas a nivel mundial. comp. Bernardo Kliksberg. CLAD, PNUD, Fondo de Cultura Económica. Caracas.

Bozeman, Barry (1998). Todas las organizaciones son públicas. Tendiendo un puente entre las teorías corporativas privadas y públicas. Fondo de Cultura Económica, México.

Brockmann, Heiner (1998). Política coyuntural y de crecimiento. En Economía Social de Mercado: su dimensión social. Fundación Friedrich Ebert, Editorial Nueva Sociedad, Caracas.

Cabanellas, Guillermo (1979). Diccionario Enciclopédico de Derecho Usual. 
Editorial Heliasta. 12 ${ }^{\mathrm{a}}$ Edición. Buenos Aires.

Castells, Antoni (1999). Haciendas locales, autonomía y responsabilidad fiscal. Rev. Gestión y Política Pública, Vol.VIII, №2, México.

Castell, Manuel (1999). La era de la información. Economía, sociedad y cultura. Vol. La sociedad Red. Alianza Editorial, Madrid.

Cormick, Hugo (1997). El Municipio del Conurbano Bonaerense. ¿Es posible el paso de la administración a las políticas activas?. Rev. Aportes para el Estado y la Administración Gubernamental, Año $4 \mathrm{~N}^{\circ} 8$, Buenos Aires.

De la Cruz, Rafael (1992). Ruta a la eficiencia: Descentralización de los Servicios públicos. La Descentralización de los Servicios de Salud. El caso del estado Carabobo. $1^{\circ}$ Edición, Edit. Nueva Sociedad. Venezuela.

Frost-Kumpf, Lee et al (1998). La acción estratégica y el cambio transformacional, en La gestión pública. Su situación actual, compilado por Barry Bozeman, Fondo de Cultura Económica, México.

Fuenmayor, Jennifer; Hernández, R.; Moreno, J. y Vargas, M.F. (2000). Evolución constitucional y perspectiva actual del Municipio en Venezuela. Rev. Ciencias de Gobierno, Año 4 №7, Maracaibo, Venezuela, pp. 99-116.

IAPEM (1997). Manual Básico para la Administración Municipal. Instituto de Administración Pública del estado de México. Toluca, México.

Mattos, Carlos de (1990). La Descentralización ¿Una nueva panacea para impulsar el desarrollo local? Rev. Economia y Sociedad, No3, Santiago de Chile, pp. 165-178.

Ochoa Henríquez, Haydée y Gamboa de Rangel ${ }_{3}$ Teresa (1983). La Gestión o Ad- ministración: un enfoque teórico-metodológico. Rev. de Ciencias Sociales, N`3 Facultad de Ciencias Económicas y Sociales de la Universidad del Zulia Maracaibo, Venezuela. pp 4371.

Osborne, David y Gaebler (1994). La Reinvención del Gobierno. La influencia del espiritu empresarial en el sector público. Editorial Piados, Barcelona, España.

Rojas Hurtado, Fernando (1995). La Descentralización Fiscal en América Latina. Reforma y Democracia, N'3, CLAD, Caracas, pp. 7-46.

Ruiz Blanco, Eliécer (1993). Derecho tributario municipal. Ediciones Libra, C.A. Caracas.

Savy, Robert (1990). La Descentralización y las Autonomias Territoriales. La Experiencia Internacional. Relaciones entre el Gobierno central y las Colectividades Territoriales. Editorial gráficas Chemar, C.A. Maracaibo, Venezuela.

Serra Rojas, Andrés (1999). Diccionario de Ciencia Política. Facultad de Derecho UNAM, Fondo de Cultura Económica, México.

Touraine, Alain (1999). ¿Podremos vivir juntos? La discusión pendiente: El destino del hombre en la aldea global. Fondo de Cultura Económica, Sao Paulo, Brasil

Yuralivker, David (1992). América Latina: nuevas perspectivas de desarrollo. En América Latina: opciones estratégicas de desarrollo. Editorial Nueva Sociedad, Caracas.

\section{Documentos Legales}

Asamblea Nacional Constituyente (1999). Constitución de la República Bolivariana de Venezuela. Caracas. 
Congreso de la República de Venezuela (1974), Ley Orgánica de Hacienda Püblica Nacional. Caracas.

Congreso de la República de Venezuela (1983). Ley Orgánica de Ordenación del Territorio. Caracas.

Congreso de la República de Venezuela (1987). Ley Orgánica de Ordenación Urbanistica. Caracas.

Congreso de la República de Venezuela (1989). Ley Orgánica de Descentralización, Dellmitación y Transferencia de Competencias del Poder Público. Caracas.
Congreso de la República de Venezuela (1989). Ley Orgánica de Régimen Municipal. Caracas.

Congreso de la República de Venezuela (1994). Código Orgánico Tributario. Caracas.

Congreso de la República de Venezuela (1997). Ley Orgánica del Sufragio y Participación Política. Caracas. 